Dokuz Eylül Üniversitesi-Mühendislik Fakültesi Fen ve Mühendislik Dergisi

Cilt 20, Sayı 59, Mayıs, 2018
Dokuz Eylul University-Faculty of Engineering Journal of Science and Engineering Volume 20, Issue 59, May, 2018

DOI: $10.21205 /$ deufmd. 2018205943

\title{
Dişçi Delgisi Gürültüsü için Aktif Gürültü Denetleyici Tasarımı ve Uygulaması
}

\author{
Hakan KAHRAMAN' ${ }^{\text {, Hatice DOĞAN*2 }}$
}

${ }^{1}$ Dokuz Eylül Üniversitesi, Fen Bilimleri Enstitüsü, Elektrik-Elektronik Mühendisliği ABD , 35160, İZMIR. (ORCID: 0000-0002-5995-6862)

${ }^{2}$ Dokuz Eylül Üniversitesi, Mühendislik Fakültesi, Elektrik-Elektronik Mühendisliği Bölümü, 35160, İZMİR. (ORCID: 0000-0003-0420-592X)

(Alınış / Received: 09.10.2017, Kabul / Accepted: 26.02.2018, Online Yayınlanma / Published Online: 15.05.2018)

Anahtar Kelimeler Özet: Dişçi delgileri yüksek frekanslı, hastaları rahatsız eden ve Aktif Gürültü Kontrolü, Normalize FxLMS, Gürültü bastırma gürültü olarak adlandırılabilecek bir ses çıkartırlar. Dişçi delgisi sesi, rahatsız edici olmasının yanı sıra insan sağlı̆̆ üzerinde olumsuz etkilere sahiptir, bu nedenle gürültü kontrol yöntemleriyle bastırılması gereklidir. Bu çalışmada dişçi delgi sesi, mikrofonlar, hoparlör ve sayısal işleme kartından oluşan bir Aktif Gürültü Kontrol (AGK) sistemiyle açlk alanda bastırılmaya çalışılmıştır. Çalışma, kullanılan yordam ve yüksek frekanslı bir gürültünün AGK yöntemiyle açık alanda bastırılmaya çalıșılması yönlerinden yazında yer alan AGK çalışmalarından farklılık göstermektedir. Uygulama sonuçlarına göre önerilen AGK sisteminin başarımı tatmin edicidir.

\section{Active Noise Controller Design and Implementation for Dental Drill Noise}

\begin{abstract}
Keywords
Active Noise

Control, Fx-LMS,

Noise Reduction.

Abstract: Dental drills produce a high frequency sound that disturbs the patients and can be called as noise. The sound of dentist drill is not only disturbing but also has adverse effects on human health so it is needed to be suppressed with noise control methods. In this study, the dentist drill noise has tried to be suppressed in open field with an Active Noise Control (ANC) system that consists of microphones, speaker and a digital signal processing card. The study differs from the ANC studies in the literature in terms of the algorithm used and the attempt to suppress a high frequency noise with ANC method in an open field. According to the implementation results, the performance of the proposed ANC system is satisfactory.
\end{abstract}

*Sorumlu yazar: hatice.dogan@deu.edu.tr 


\section{Giriş}

Diş doktorlarının tedavi sırasında kullandıkları delgilerin çıkarmış oldukları sesler oldukça tedirgin edicidir ve hastaya ciddi bir rahatsızlık vermektedir. Yapılan araştırmalara göre insanlar en çok diş dolgusu esnasındaki tiz oyma sesi nedeniyle diș doktoruna gitmekten ve tedavi olmaktan çekinmektedir. Dişçi delgisi sesinin hastalar üzerindeki olumsuz etkilerinin yanı sıra bu sese uzun süre maruz kalan diş doktorları ve teknisyenlerinin işitsel konuda geri dönüșü olmayan bir kayba uğradıkları bilinmektedir [1]. Bu sesin, istenmeyen etkilerinin ortadan kaldırılması için gürültü kontrol yöntemleriyle bastırılması gereklidir.

Gürültü kontrolü yöntemleri aktif, pasif ve hibrit gürültü kontrol yöntemleri olarak üç ana başlıkta incelenebilir. Pasif gürültü kontrolü (PGK) izolatörler, ses emiciler, ve susturucular gibi izolasyon malzemeleri kullanılarak ortamdaki gürültünün azaltılmasıdır. AGK sisteminde ise mikrofonla alınan gürültü sinyaline eşit genlikte ters fazda bir sinyal uyarlamalı bir filtre aracılığıyla oluşturulup hoparlör aracıllğılyla ortama verilerek, gürültü ve sinyalin birbirini sönümlendirmesi sağlanır [5]. AGK bebek küvezlerinin [6], hastanelerdeki FMRI cihazlarının [7], otomobil kabinlerinin [89] ve havalandirma sistemi [10] gürültülerinin giderilmesi gibi oldukça geniş bir uygulama yelpazesine sahiptir. Her iki kontrol yönteminin kullanıldığ 1 sistemler hibrit olarak adlandırılırlar.

AGK düşük frekanslı gürültüleri bastırmak için kullanılmasına rağmen Kaymak ve diğerleri bu yöntemin yüksek frekanslı diş̧̧i delgilerinin gürültülerinin bastırılması için de kullanılabileceğini göstermişlerdir [3-4]. $\mathrm{Bu}$ çalışmada yüksek frekanslı gürültünün sadece PGK yöntemiyle tam olarak bastırılamadığı AGK yöntemlerinin de kullanılması gerektiği belirtilmiş, öncelikle sesin karakteristiği ve baskın frekansı belirlenmiștir. Belirlenen ana frekansın bastırılması için yazında oldukça sık başvurulan AGK yöntemlerinden biri olan filtrelenmiş-x en küçük ortalama kareler (FxLMS) yordamı kullanılmıştır. PGK yönteminin avantajlarından da yararlanmak için sistem kulaklık üzerine monte edilmiş, ikincil yolun parametreleri çevrimdışı hesaplanarak sabitlenmiștir. [3]'deki sistemden farklı olarak bu çalışmada dişçi delgisi sesi sadece AGK yöntemiyle açık alanda bastırılmaya çalışılmıștır. AGK yordamlarından normalize edilmiş FxLMS kullanılmış ve ikincil yolun parametreleri çevrimiçi yöntemle hesaplanmıştır. İkincil yol, sayısal/ analog, analog/sayısal çeviriciler, filtreler gibi donanım bileșenlerinin ve hoparlör ile mikrofon arasındaki akustik yolun etkilerini temsil etmektedir.

Makale şu şekilde düzenlenmiştir: 2 . Bölümde diş̧̧i delgisi gürültüsünü bastırmak için kullanılan AGK sisteminin teorisi ve donanımı anlatılmış, 3. Bölümde yapılan deneyler ve elde edilen sonuçlar verilmiștir. 4. Bölümde ise sonuçların yorumlanması ve karşılaştırılması verilmiştir.

\section{2. Önerilen Sistem}

Diş delgisi sesini bastırmak için kullanılacak sistem, AGK ve donanım ana başlıkları altında incelenebilinir.

\subsection{Aktif Gürültü Kontrolü}

AGK sistemleri yok edilmek istenen gürültü sinyalinin ulaşılabilir olup olmamasına göre geri beslemeli, ileri beslemeli ve bu ikisinin bileșimi olarak üç ana başlıkta incelenir. Gürültü sinyalinin ulaşılabilir olmadığı durumlarda geri beslemeli AGK sistemleri kullanılır. Bu sistemler daha kompakt ve düşük maliyetli olmalarına karşın gürültünün sadece öngörülebilir bileşenlerini zayıflatabilirler ve ileri beslemeli AGK'lara göre daha az dayanıklıdırlar 
[11]. Bu sınırlamalarından ötürü işitme cihazları gibi belirli uygulamalarda kullanılabilirler [11]. Bu çalışmada gürültü sinyalinin ulaşılabilir olması ve geri beslemeli AGK'nın bahsedilen dezavantajlarından dolayı, diş delgisi sesinin $\quad 0-4 \mathrm{kHz}$ frekans aralığında bastırılması için ileri-beslemeli AGK yöntemi kullanılmıştır.

Literatürde, aktif gürültü kontrolünde uyarlamalı filtre katsayılarının bulunması için birçok farklı yöntem önerilmiştir. Bu yöntemler içinde düşük hesaplama karmaşıklığına sahip olması, dayanıklılığı ve uygulanmasinın kolay olmasından dolayı LMS yordamı en sıklıkla kullanılan yöntem olmuştur [12]. LMS yordamı kullanan ileri beslemeli AGK sisteminin blok diyagramı Şekil 1'de verilmiştir.

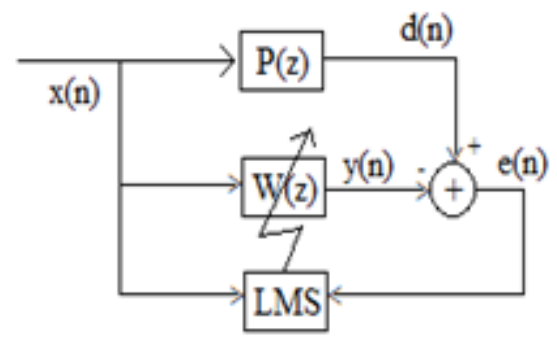

Şekil 1: İleri beslemeli AGK - LMS

İleri beslemeli AGK yönteminde uyarlamalı filtre W(z)'nin katsayıları LMS yordamı kullanılarak güncellenir. Uyarlamalı filtre tarafından, $d(n)$ sinyaline eşit genlikte ters fazda $y(n)$ sinyali üretilir. Hoparlörle ortama verilen $y(n)$ sinyali hata mikrofonuna ulaşarak, burada sessiz bir bölge oluşturur. $x(n)$ gürültü kaynağından çıkan sinyal, $\mathrm{P}(\mathrm{z})$ ise gürültü kaynağı ile hata mikrofonu arasındaki birincil akustik yoldur

LMS yordamının temel fikri, filtre katsayılarını optimum filtre katsayılarına yaklaşacak şekilde güncellemektir. Filtre katsayıları gradyan iniş yordamına göre güncellenir [11]. Yordam küçük katsayı değerleriyle başlar ve her adımda ortalama karesel hatanın gradyanına göre katsayılar güncellenir. Katsayı güncelleme kuralı (1) denklemiyle verilmiştir.

$w(n+1)=w(n)+\mu x(n) e(n)$

Burada $\mu$ parametresi adim büyüklüğüdür. $\mathrm{Bu}$ parametrenin seçimi yordamın başarımı açısından kritiktir. Çok büyük basamak değeri seçmek yordamın yakınsamasını etkilerken, küçük değer seçmek ise yakınsama zamanının uzamasına neden olabilir.

Literatürde, LMS yordamının birçok farklı çeșidi bulunmaktadır. Normalize LMS (NLMS), Sign-Error LMS, Sign-Data LMS ve Sign-Sign LMS bu yöntemlerin en bilinenleri arasındadır [12]. Benzetim ortamında, dişçi delgisi sesi için bu yöntemler denenmiş ve en iyi başarım NLMS yordamiyla elde edildiğinden bu çalışmada NLMS yönteminin gerçek hayata uyarlanmış şekli olan normalize FxLMS yordamı kullanılmıştır.

NLMS yordamında, yordamın $\mu$ parametresinin, seçiminin etkilerinden bağımsız olabilmesi için (1) denkleminin sağındaki ikinci terim giriş sinyalinin karesi ile normalize edilmiştir. Buna göre katsayı güncelleme kuralı (2) numaralı denklemde verilmiştir.

$$
w(n+1)=w(n)+\mu \frac{e(n) x(n)}{c+\|x(n)\|^{2}}
$$

Burada c paydanın sıfır olmasını engelleyen birden çok küçük bir sabittir.

Pratikte NLMS yordamı ile katsayıları güncellenen filtrenin çıkışı olan sinyal, eleme noktasına ulaşıncaya kadar hoparlör ile hata mikrofonu arasında kalan akustik yolu almak zorundadır. Çeviriciler, filtreler gibi donanım bileşenlerinin gecikme etkileri de bu yola eklenerek ikincil yol olarak adlandırılır. İkincil yol $\mathrm{S}(\mathrm{z})$ filtre çıkış sinyalinde gecikme meydana getirir ve bu da hata 
sinyali ile referans sinyali $d(n)$ arasinda senkronizasyon hatası oluşturur. $\mathrm{Bu}$ nedenle AGK sisteminin başarımı için ikincil yolun tahmin edilerek sisteme eklenmesi gerekir. FxLMS yordamı, istikrarlı öngörülebilir çalışması nedeniyle aktif gürültü kontrolünde bugüne kadar en çok kullanılan yöntemlerden biri olmuştur [13-16]. Normalize FxLMS yordamı kullanan ileri beslemeli AGK sisteminin blok diyagramı Şekil 2'de verilmiștir. Burada hata sinyali $e(n)$, birincil yol üzerinden gelen gürültü sinyali $d(n)$ ile filtre tarafından üretilip, hoparlör aracilığıyla ortama verilen ve ikincil yol $\mathrm{S}(\mathrm{z})$ üzerinden gelen $\hat{y}(n)$ sinyalinin farkıdır.

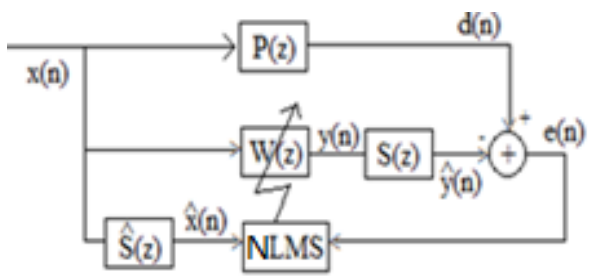

Şekil 2: İleri beslemeli AGK-NFxLMS

İkincil yolun etkilerini de içeren normalize FxLMS yordamının filtre katsayıları güncelleme kuralı (3) denklemiyle verilmiştir.

$$
w(n+1)=w(n)+\mu \frac{e(n) \hat{x}(n)}{c+\|\hat{x}(n)\|^{2}}
$$

İkincil yolun tahmin edilmesi çevrimiçi ve çevrimdışı olmak üzere iki yöntem önerilmiştir. Çevrimdışı yöntemde filtre katsayıları bir kez belirlenir ve sabitlenir. $\mathrm{Bu}$ yöntemin uygulaması daha kolay olmakla birlikte ikincil yolda meydana gelen sicaklık, nem ve mesafe değişimlerine karşı duyarsız olduğu için başarımı çevrimiçi yönteme göre daha kötüdür. $\mathrm{Bu}$ çalışmada çevrimiçi yöntemlerden Eriksson modeli kullanılmıştır [17]. Eriksson S(z) modelini içeren AGK sisteminin blok diyagramı Şekil 3'de verilmiştir.
Eriksson yönteminde, S(z)'yi tahmin edebilmek için AGK sisteminin çevrimiçi çalışması sırasında, sisteme ikinci bir uyarlanabilir filtre eklenir ve bu filtre kullanılarak beyaz gürültü yok edilmeye çalışılır.

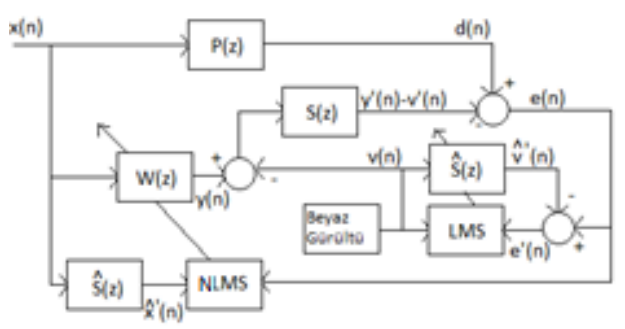

Şekil 3: Eriksson ikincil yol modeli içeren AGK

Burada $y(n)$ ana filtrenin çıkışı, $d(n)$ yok edilmek istenen sinyal, $e(n)$ hata sinyali, $v(n)$ beyaz gürültü, $y^{\prime}(n)$ ve $v^{\prime}(n)$ ikincil yol üzerinden gelen filtre çıkışları, $e^{\prime}(n)$ ise ikinci filtrenin hata sinyalidir. $\mathrm{Bu}$ durumda $e(n)$ ve $e^{\prime}(n)$ sinyalleri aşağıdaki denklemlerle hesaplanır.

$$
\begin{gathered}
e(n)=\left[d(n)-y^{\prime}(n)\right]+v^{\prime}(n) \\
e^{\prime}(n)=e(n)-\widehat{v}^{\prime}(n) \\
=\left[d(n)-y^{\prime}(n)\right] \\
+\left[v^{\prime}(n)-\widehat{v}^{\prime}(n)\right] \\
\hat{s}(n+1)=\hat{s}(n)+\mu_{s} e^{\prime}(n) v(n) \\
+\mu_{s} v(n)\left[v^{\prime}(n)-\widehat{v}^{\prime}(n)\right]
\end{gathered}
$$

$\hat{S}(\mathrm{z})$, ikincil yol $\mathrm{S}(\mathrm{z})$ 'nin tahminidir. Sistem, $\quad v^{\prime}(n)-\hat{v}^{\prime}(n) \quad$ farkı sifira yaklaştıkça d(n) sinyalini $y^{\prime}(n)$ çıkışıyla yok eden basit bir LMS sistemi haline gelir. Beyaz gürültünün kullanılmasının nedeni, tüm frekans değerlerini içermesi ve AGK sistemini olası tüm ikincil yol etkileri için hazırlamasıdır.

\subsection{AGK Donanımı}

Diş̧̧i delgisi için değiş̧ik hızlarda dönüş hızına sahip (2500-3000rpm), pedallı bir 
delgi modeli seçilmiştir. Kullanılan donanımsal düzenekte, yok edilmek istenen sinyalin, gürültü kaynağından çıkan sesin ve hata sinyallerinin sayısal işleme kartına aktarılması ve gözlemlenebilmesi için üç adet mikrofon ve $110-15.000 \mathrm{~Hz}$ aralığında çalışabilen bir hoparlör kullanılmıștır. Mikrofonların frekans cevapları 20kHz'e kadar çıkabilmektedir. Akustik geri beslemenin en aza indirgenmesi için kullanılan mikrofonlar tek yönlü olarak seçilmiştir.

Mikrofonlarla kaydedilen analog sinyaller yükseltilerek, analog/sayısal çevirici olan ADC 0804 entegresi aracılığıyla dijital bir sinyale dönüştürülmüştür. Sayısal işaret işleme için Texas Instruments'n 32 bitlik işlemciye sahip TMS320F28335 eZdsp kartı seçilmiştir. İşlemci hızı 150MHz'e kadar ulaşabilen bu kartta $3.3 \mathrm{~V}$ ile beslenen 87 adet giriş çıkış mevcuttur. Kart dâhilinde analog bir çıkış bulunmamaktadır. $256 \mathrm{~K}, 128 \mathrm{~K}$ ve $64 \mathrm{~K}$ boyutlarında 16'şar Flash hafıza mevcuttur. Tasarlanan sistemin temsili Şekil 4'te verilmiştir.

Sistemin performansının gerçek ortamda gözlenebilmesi için sessizleștirilmek istenen bölge ses kaynağına $5 \mathrm{~cm}$ uzaklıkta seçilmiştir. Bu uzaklı̆̆ın bulunması için $1 \mathrm{~cm}$ ile $10 \mathrm{~cm}$ arasındaki uzaklıklar denenmiş delgi sesinin ortalamada en iyi bastırılabildiği uzaklık 5 $\mathrm{cm}$ olarak tespit edilmiştir. Tasarlanan sistem kulaklık üzerine monte edildiğinde diş delgisi ile arasındaki olası mesafe göz önüne alınarak bu mesafeler test edilmiştir. Mikrofonlardan bir tanesi gürültü kaynağının önüne yerleștirilmiş ve $x(n)$ sinyalinin kaydı için kullanılmıştır. Hata mikronu e(n) sinyalinin gözlenmesi amacıyla sessizleştirilmek istenen bölgeye yerleștirilmiștir. Mikrofon ile kaydedilen sesler bir analogdan sayısala çevirici aracılığıyla TMS320F28335 eZdsp kartının girişine verilmiş burada tekrar ters fazda üretilen sinyal bir bașka hoparlör tarafından ortama verilmiştir.
Normalize FxLMS yordamı MATLAB'in Simulink toolbox'ı kullanarak gerçeklenmiştir. Simulink toolbox'ı sayısal işleme kartının da kütüphanelerini içermesi nedeniyle seçilmiştir. Sayısal sinyal işleme kartında normalize edilmiş FxLMS yordamı kullanılarak üretilen sayısal sinyal, DAC0800 entegresi kullanılarak analog forma dönüştürülüp hoparlöre iletilmiștir.

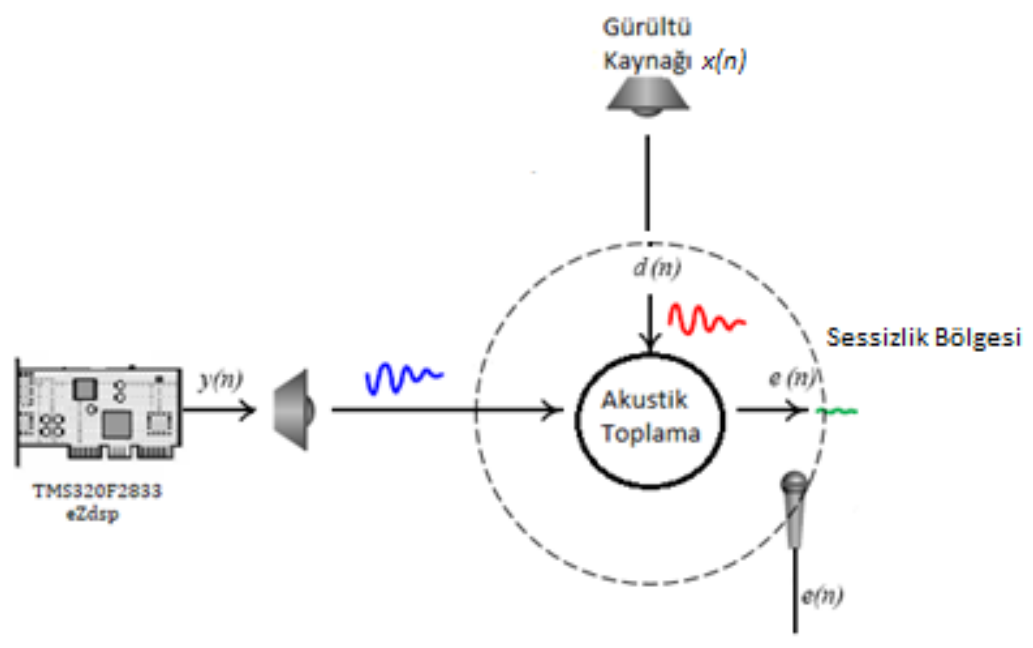

Şekil 4: Tasarlanan Sistem 


\section{Bulgular}

\subsection{Veri Seti}

AGK uygulanmadan önce dişçi delgisi sesi analiz edilmelidir. Bu nedenle delgi farklı çalışma koşullarında çalıștırılarak 40 farklı delgi sesi, 30 saniye süresince kaydedilmiştir. Bu 40 sesten 20 tanesi delgi boşta çalıştırılırken, 20 tanesi de farklı delme ișlemleri sırasında kaydedilmiştir. İki farklı ses örneği ve güç spektral yoğunlukları Şekil 5 ve Şekil 6'da verilmiştir
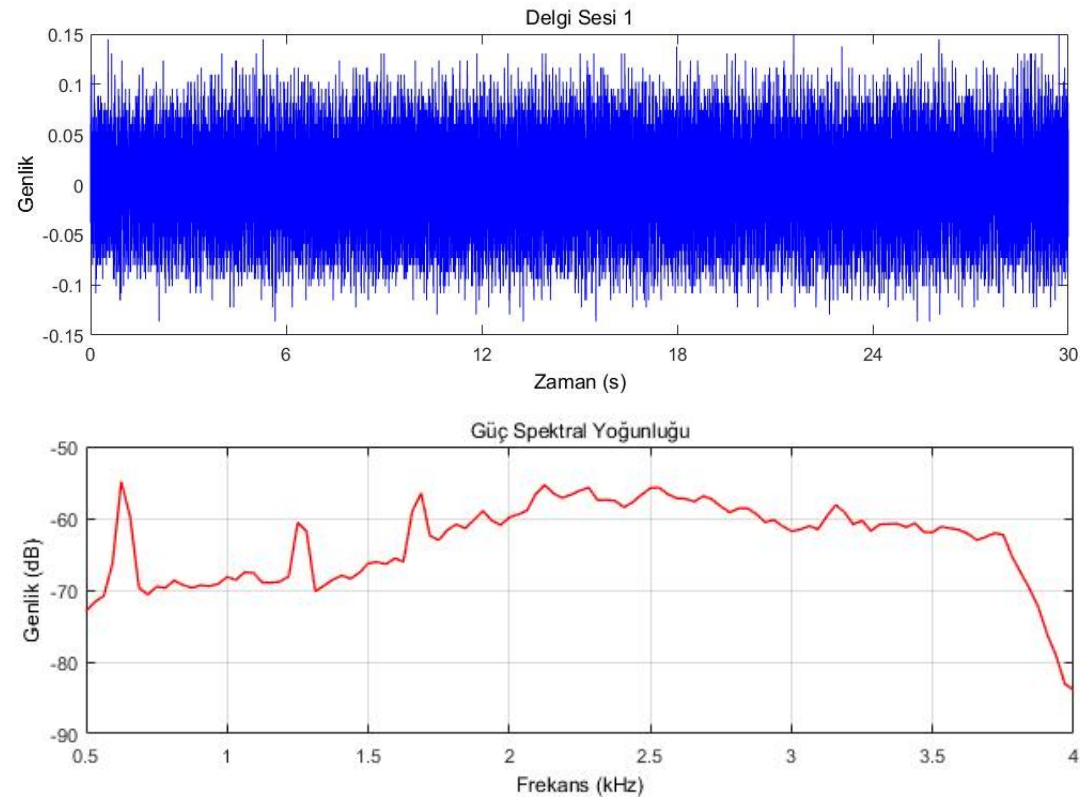

Şekil 5: Dişçi delgisi boşta çalışma örneği ve güç spektral yoğunluğu
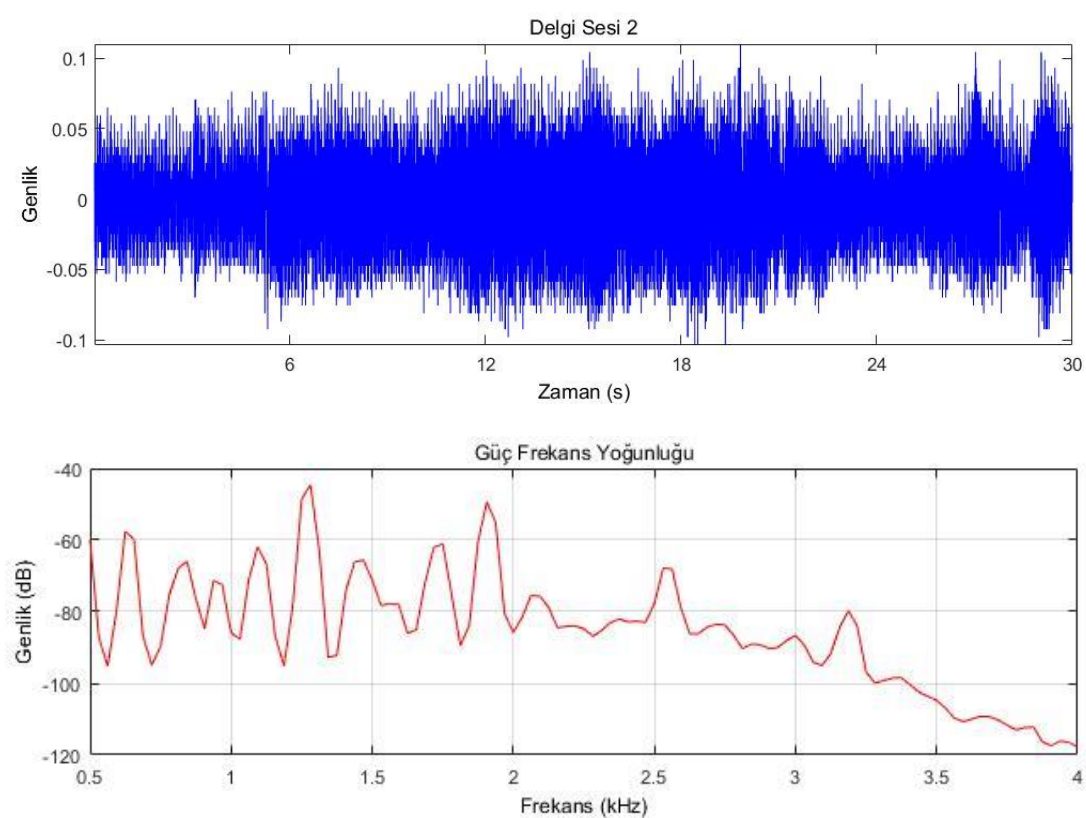

Şekil 6: Delme işlemi sırasında dişçi delgisi sesi örneği ve güç spektral yoğunluğu 
Delgi boşta çalışırken kaydedilen örnek Delgi Sesi 1, delme işlemi sırasında kaydedilen örnek Delgi Sesi 2 olarak gösterilmiştir. Bu iki örneğin güç spektral yoğunluk grafiklerine bakıldığında farklı karakteristiklere sahip oldukları gözlemlenebilir. Kaymak ve diğerlerinin çalıșmalarında dișçi delgisi sesi analiz edilip 2.5 ve $3.3 \mathrm{kHz}$ frekanslarındaki baskın gürültü yok edilmeye çalışılmıştır.

Bu çalışmada ise 0-4 kHz bandındaki tüm gürültü bileşenleri bastırılmaya çalıșılmıştır. Daha yüksek frekanslardaki

gürültüyü AGK ile yok etmeye çalışmak, oluşturulacak sessiz bölgenin çapının çok küçük olmasına neden olacağından anlamlı değildir.

\subsection{Benzetim ve Deney Sonuçları}

En iyi başarımı veren yordamı tespit etmek için LMS yordamı ve çeșitleri NLMS, Sign-Error LMS, Sign-Data LMS ve Sign-Sign LMS yordamları benzetim ortamında, dişçi delgisi sesi için denenmiş ve hata sinyalinin genliğine karşı iterasyon grafiği Şekil 7'de verilmiştir.

IUS

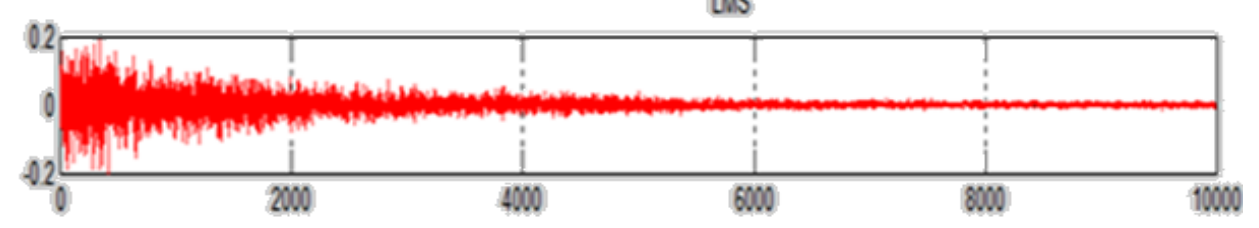

NUS

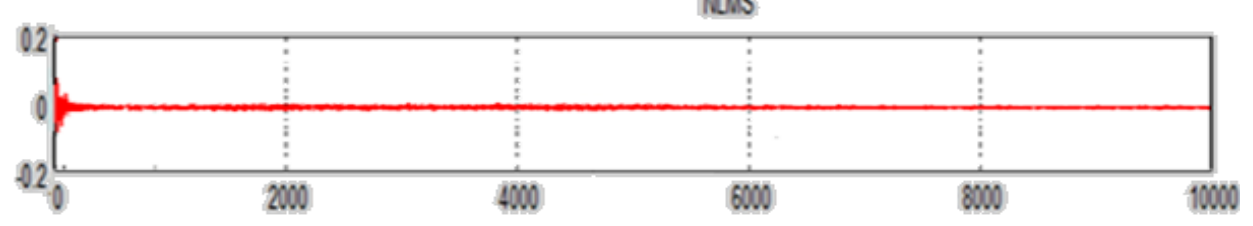

Signeror LUS

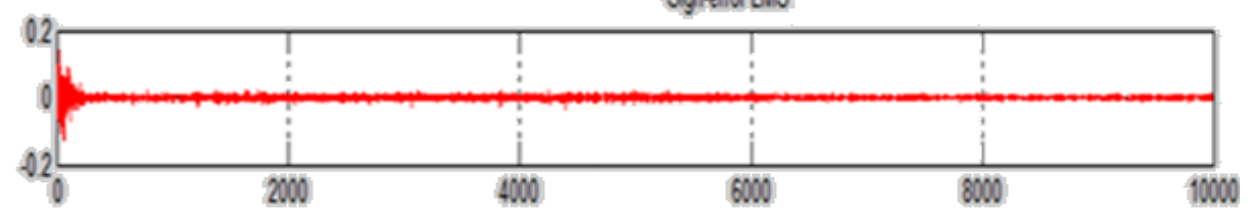

SigndataluS

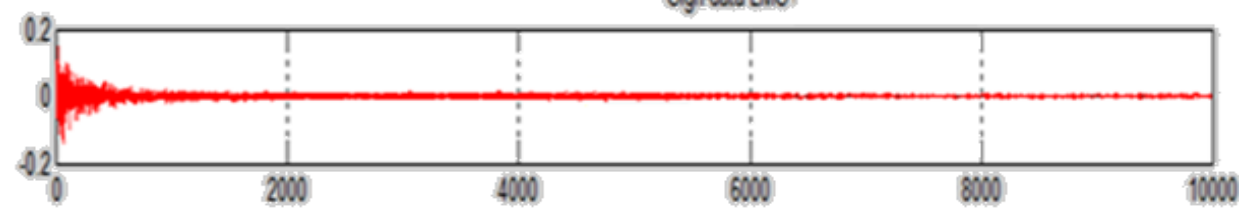

Sign-sign LUS

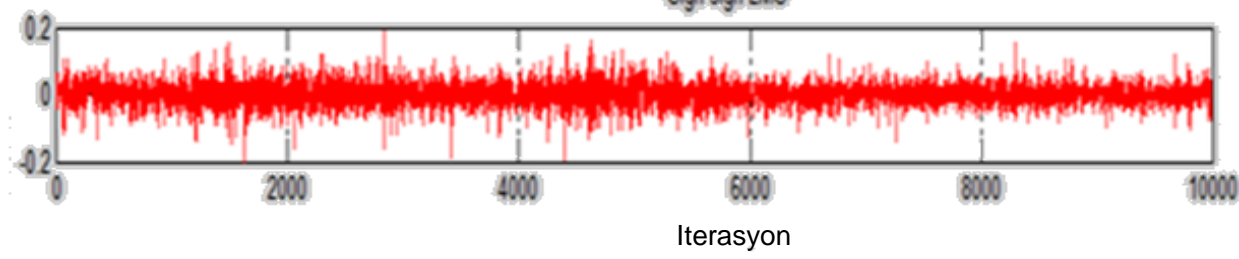

Şekil 7: Farklı yordamların iterasyona karşı hata genliği grafikleri 
Şekil 7 incelendiğinde Sign-Sign LMS yordamının yakınsamadığı LMS yordamının ise yakınsama süresinin diğerlerinden daha uzun olduğu görülmüștür. Diğer yordamlarla karşıllaştırıldığında da en hızlı ve en iyi NLMS yordamının yakınsadı $\breve{g}$ sonucuna varılmıştır.

NMLS yordamı için basamak genişliği ve süzgeç uzunluğu belirlenmesi gereken iki önemli parametredir ve bu parametreler için optimal değerler yapılan benzetimler sonucu sirasiyla 0.001 ve 256 olarak bulunmuştur.
Şekil 8 ve Şekil 9'da iki farklı delgi sesine ait yok edilmek istenen $d(n)$ ve hata $e(n)$ sinyallerinin güç spektral yoğunlukları frekansa göre çizilmiştir. Şekilden de görüldüğü gibi gürültünün elenmesi başarılı bir şekilde gerçekleştirilmiştir.

NLMS yordamının benzetim ortamında performansı, kaydedilmiș 40 farklı delgi sesi için ölçülmüş ve ortalamada $17.5 \mathrm{~dB}$ olarak hesaplanmıştır. Sistem sadece benzetim ortamında çalıştırıldığı için performansı oldukça yüksek çıkmıştır.

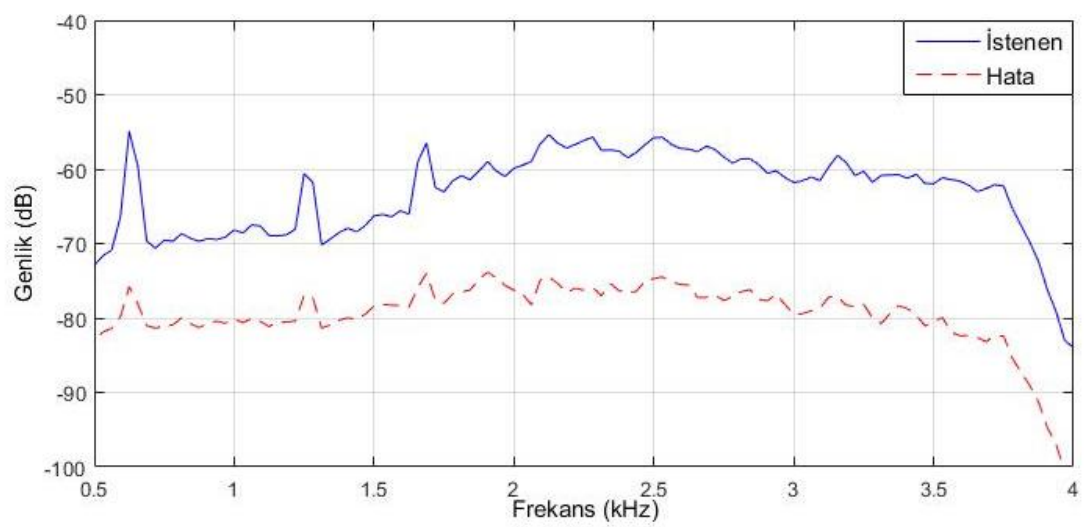

Şekil 8: Dişçi delgisi boșta çalışırken, yok edilmek istenen d(n) ve hata e(n) sinyallerinin güç spektral yoğunlukları benzetim sonuçları

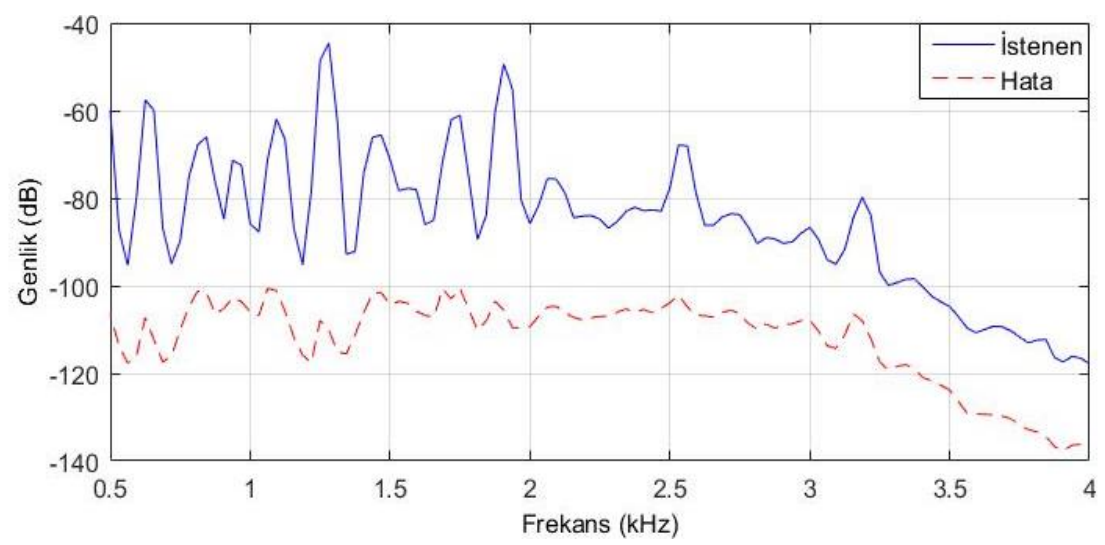

Şekil 9: Dişçi delgisi delme işlemi sırasında, yok edilmek istenen d(n) ve hata e(n) sinyallerinin güç spektral yoğunlukları benzetim sonuçları 
Sistemin açık alanda gürültü bastırma başarımının ölçümü için Şekil 4'te temsili verilen sistem düzeneği üzerinde deneyler yapılmıştır.

Şekil 10'da, delgi boşta çalıştırılırken, Şekil 11 'de ise delme işlemi sırasında kaydedilmiş delgi seslerinin tasarlanan sistem düzeneği ve normalize FxLMS yordamıyla açı alanda bastırılma sonuçlarını göstermektedir. Şekiller incelendiğinde gürültünün farklı frekanslarda farklı oranlarda bastırıldığ gözlemlenebilir. Tasarlanan sistemle genel olarak gürültünün başarılı bir şekilde bastırıldığı görülmektedir. 40 adet delgi sesi için sistemin ortalama SNR performansı tüm frekanslar üzerinden 6 $\mathrm{dB}$ olarak hesaplanmıștır.

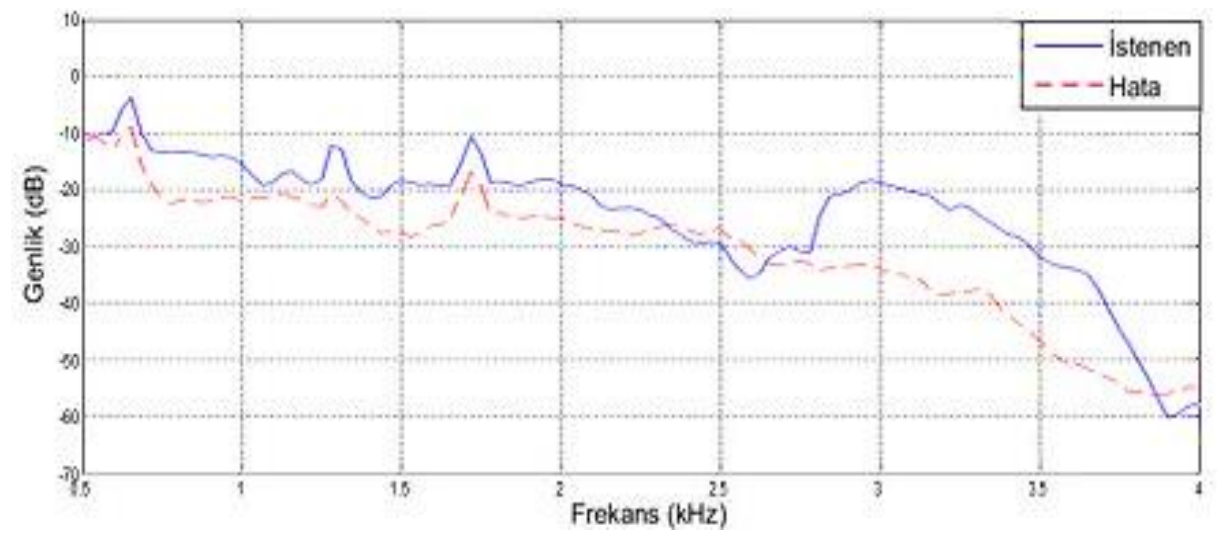

Şekil 10: Dişçi delgisi boşta çalışırken, yok edilmek istenen d(n) ve hata e(n) sinyallerinin güç spektral yoğunlukları gerçek ortam sonuçları

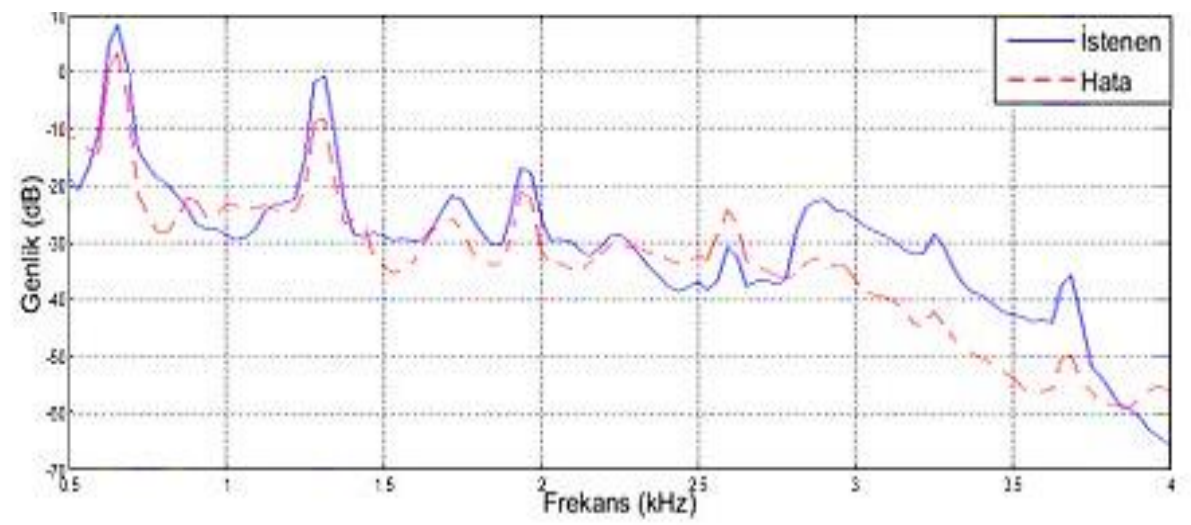

Şekil 11: Dişçi delgisi delme işlemi sırasında, yok edilmek istenen d(n) ve hata e(n) sinyallerinin güç spektral yoğunlukları gerçek ortam sonuçları

\section{Tartıșma ve Sonuç}

Bu çalışmada yüksek frekanslı diş delgisi gürültüsü AGK yöntemi Normalize FxLMS yordamı ile $0-4 \mathrm{kHz}$ bandında, açık alanda bastırılmaya çalışılmıştır.

\begin{abstract}
Hazırlanan donanım ile yapılan çalışmalar sonucunda gürültünün ortalamada $\quad 6 \mathrm{~dB} \quad$ bastırıldığ gözlenmiştir. Açık alanda AGK yöntemiyle gürültü bastırmaya yönelik
\end{abstract}


çalışmalardan biri olan kamyon kabinlerindeki gürültünün bastırılmasında kullanılan üç kanal ANC sisteminde Fx-LMS yordamiyla ortalamada 3dB'lik bir zayıflatma başarımı rapor edilmiştir [9]. Kaymak ve diğerlerinin çalışmasında tek bir ses örneğinde $3.3 \mathrm{khz}$ frekansında 30dB'nin üzerinde bir zayıflama rapor edilmiştir [3]. Bu çalışmada hem AGK hem de PGK kullanılmış ve tek bir frekans değerindeki $(3.3 \mathrm{kHz})$ zayıflama rapor edilmiştir [3].

Yüksek frekanslı gürültülerde AGK yöntemi kullanımının dezavantajı oluşturulmak istenen sessiz bölgenin çapının frekansla ters orantılı olarak küçük olmasıdır. $\mathrm{Bu}$ dezavantaj tasarlanan sistemin kulaklık üzerine monte edilmesiyle ortadan kaldırılabilinir. Kulaklık üzerinde PSK yöntemlerinin de kullanımıyla yüksek frekanslardaki gürültünün daha yüksek oranda bastırılması mümkündür.

\section{Teşekkür}

Bu çalışma 2012.KB.FEN.051 numaralı Dokuz Eylül Üniversitesi Bilimsel Araştırma Projesi tarafından desteklenmiștir.

\section{Kaynakça}

[1] Zubick H.H., Tolentino, A.T., Boffa, J. 1980. Hearing Loss and the High Speed Dental Handpiece, American Journal of Public Health, Cilt.70, no:6, s. 633-635.

[2] Theodoroff, S. M., Folmer, R. L. 2013. Hearing Loss Associated with Long-Term Exposure to HighSpeed Dental Handpieces, General Dentistry.

[3] Rotter, K. R. G. R., Atherton, M. A., Kaymak, E., ve Millar, B. J. 2008. Noise reduction of dental drill noise. Mechatronics 2008, 23-25 Haziran, İrlanda, 1-5.
[4] Kaymak, E., Atherton M. 2006. Active Noise Control at Higher Frequencies. The Thirteenth International Congress on Sound and Vibration, 2-6 Temmuz, Viyana, Avusturya, 275-281. DOI: 10.13140/RG.2.1.4621.2886

[5] Kuo, S. M., Morgan, D. 1995. Active Noise Control Systems: Algorithms and DSP Implementations. John Wiley \& Sons, Inc. 389s.

[6] Thanigai, P., Kuo, S. M., Yenduri, R. 2007. Nonlinear Active Noise Control For Infant Incubators in Neo-Natal İntensive Care Units. IEEE International Conference on Acoustics, Speech and Signal Processing, ICASSP 2007, 16-20 Nisan, Honolulu Amerika 109-112. DOI: 10.1109/ICASSP.2007.36662 8.

[7] Vemuri, S. H. K., Ganguly, A., Panahi, I. 2014. Real-Time Active Noise Control Of Multi-Tones And MRI Acoustic Noise in FMRI Bore with Signal Decomposition and Parallel Hybrid RLS-NLMS Adaptive Algorithms. 2014 IEEE Circuits and Systems Conference, 12-13 Ekim, Dallas, Amerika, 1-4. DOI:10.1109/DCAS.2014.6965339

[8] Wang, L., Gan, W. S., Kuo, S. M. 2008. Integration of Bass Enhancement and Active Noise Control System in Automobile Cabin. Advances in Acoustics and Vibration, Article ID 869130. DOI:10.1155/2008/869130

[9] Zou G., Antilla M., Lankila A. , Kataja J. 2009. Equalized Algorithm for A Truck Cabin Active Noise Control. http://www.akustinenseura.fi/wpcontent/uploads/2013/08/44_Zou. pdf

(Erişim Tarihi: 09.10.2017)

[10] Homma K. 2004. Compact Integrated Active - Passive 
H. Kahraman vd. / Dişçi Delgisi Gürültüsü için Aktif Gürültü Denetleyici Tasarımı ve Uygulaması

Approach for Axial Fan Noise Control, Virginia Polytechnic Institute and State Üniversitesi, Doktora Tezi, 212 s. Virginia.

[11] Ardekani, I. T., Abdulla, W. H. 2011. FxLMS-based Active Noise Control: A Quick Review. AsiaPasific Signal and Information Processing Association Annual Summit and Conference APSIPA ASC 2011, 18-21 Ekim, Xi'an, Çi,. $10 \mathrm{~s}$.

[12] Dixit, S.,, Nagaria, D. 2017. LMS Adaptive Filters for Noise Cancellation: A Review, International Journal of Electrical and Computer Engineering, Cilt. 7, no:5, s. 2520-2529. DOI: 10.11591/ijece.v7i5.pp2520-2529

[13] Deb, A., Kar, A., Chandra, M. 2014. A Technical Review On Adaptive Algorithms For Acoustic Echo Cancellation. IEEE International Conference on Communications and Signal Processing (ICCSP), 3-5 Nisan, Melmaruvathur, Hindistan, 41-45.

[14] Fang, Y., Zhu, X., Liu, H., \& Gao, Z. 2017. Hybrid Fx-NLMS Algorithm for Active Vibration Control of Flexible Beam with Piezoelectric Stack Actuator. In Advanced Computational Methods in Life System Modeling and Simulation Springer, Singapur, 273-281. DOI: 10.1007/978-981-10-6370-1_27

[15] Chung, I. J. 2016. Multi-channel normalized FxLMS algorithm for active noise control, Journal of The Acoustical Society of Korea, Cilt. 35, No.4, s. 280-287.

DOI: 10.7776/ASK.2016.35.4.280

[16] Budati, A. N., Rao, B. B. 2014. Performance Analysis of Feedforward Adaptive Noise Canceller Using Nfxlms Algorithm, International Journal of Innovative Research in Electrical, Electronics,
Instrumentation and Control Engineering, Cilt. 2, s. 1940-1944.

[17] Eriksson L. J., Allie M. C. 1989. Use of Random Noise for On-Line Transducer Modeling in An Adaptive Active Attenuation System. J. Acoust.Soc. Am., Cilt. 85, s. 797-802. 